\title{
Empirical models of Total Electron Content based on functional fitting over Taiwan during geomagnetic quiet condition
}

\author{
Y. Kakinami ${ }^{1}$, C. H. Chen ${ }^{1}$, J. Y. Liu ${ }^{1,2}$, K.-I. Oyama ${ }^{1}$, W. H. Yang ${ }^{3}$, and S. Abe ${ }^{4}$ \\ ${ }^{1}$ Institute of Space Science, National Central University, No. 300 Jhongda Rd. Jhongli City, Taoyuan 32001, Taiwan \\ ${ }^{2}$ Center for Space and Remote Sensing Research, National Central University, No. 300 Jhongda Rd. Jhongli City, Taoyuan \\ 32001, Taiwan \\ ${ }^{3}$ Department of Statistics, University of Missouri-Columbia, 146 Middlebush Hall Columbia, MO 65211-6100US, USA \\ ${ }^{4}$ Institute of Astronomy, National Central University, No. 300 Jhongda Rd. Jhongli City, Taoyuan 32001, Taiwan
}

Received: 26 November 2008 - Revised: 27 April 2009 - Accepted: 19 August 2009 - Published: 26 August 2009

\begin{abstract}
Empirical models of Total Electron Content (TEC) based on functional fitting over Taiwan $\left(120^{\circ} \mathrm{E}\right.$, $24^{\circ} \mathrm{N}$ ) have been constructed using data of the Global Positioning System (GPS) from 1998 to 2007 during geomagnetically quiet condition $\left(D_{s t}>-30 \mathrm{nT}\right)$. The models provide TEC as functions of local time (LT), day of year (DOY) and the solar activity (F), which are represented by 1-162 days mean of F10.7 and EUV. Other models based on median values have been also constructed and compared with the models based on the functional fitting. Under same values of F parameter, the models based on the functional fitting show better accuracy than those based on the median values in all cases. The functional fitting model using daily EUV is the most accurate with 9.2 TECu of root mean square error (RMS) than the 15-days running median with $10.4 \mathrm{TECu}$ RMS and the model of International Reference Ionosphere 2007 (IRI2007) with 14.7 TECu RMS. IRI2007 overestimates TEC when the solar activity is low, and underestimates TEC when the solar activity is high. Though average of 81 days centered running mean of F10.7 and daily F10.7 is often used as indicator of EUV, our result suggests that average of F10.7 mean from 1 to 54 day prior and current day is better than the average of 81 days centered running mean for reproduction of TEC. This paper is for the first time comparing the median based model with the functional fitting model. Results indicate the functional fitting model yielding a better performance than the median based one. Meanwhile we find that the EUV radiation is essential to derive an optimal TEC.
\end{abstract}

Keywords. Ionosphere (Equatorial ionosphere; Ionospheric disturbances) - Radio science (Ionospheric physics)

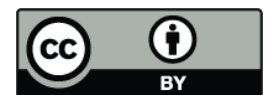

Correspondence to: Y. Kakinami (kaki@jupiter.ss.ncu.edu.tw)

\section{Introduction}

The dual frequency radio signals of the Global Positioning System (GPS) are widely used to estimate ionospheric Total Electron Content (TEC), which is one of the most powerful techniques to observe ionosphere. Many ionospheric phenomena, such as traveling ionospheric disturbances (Saito et al., 2001), large scale traveling ionospheric disturbances during magnetic storm (Tsugawa et al., 2003) and tunami ionospheric disturbance after a large earthquake (Liu et al., 2006a), have been revealed by GPS-TEC. One of the most pronounced researches investigated by GPS-TEC is preseismic ionospheric perturbations (Liu et al., 2000, 2001, 2004). The ionospheric perturbations caused by the earthquakes are small as compared with local time (LT), seasonal and solar flux variation. Thus references for the researches are quite important to study the precursor phenomena related to the earthquakes. Previous studies used 15-days running median of GPS TEC, which is defined as previous 15 days median, as the reference for earthquake researches (Liu et al., 2000, 2001, 2004). Though the 15-days running median is very useful, the running median has a shortcoming during high solar activity because the 15-days running median cannot follow large fluctuation of the solar activity F10.7, whose variable periods are from 13 to 40 days (Kane, 2003; Uozumi et al., 2008). The most well known reference, International Reference Ionosphere (IRI), which has been developed since 1970s (Rawer et al., 1978), is very good tool to reproduce global disturbances of lower ionosphere. However, IRI has often overestimates plasma density in upper ionosphere and TEC as many authors have pointed out (Bilitza and Williamson, 2000; Iwamoto et al., 2002; Bilitza, 2001, 2004; Bilitza et al., 2006; Kakinami et al., 2008). Hence it is underqualified to use IRI as the reference such as small and localized variation of ionosphere associated

Published by Copernicus Publications on behalf of the European Geosciences Union. 


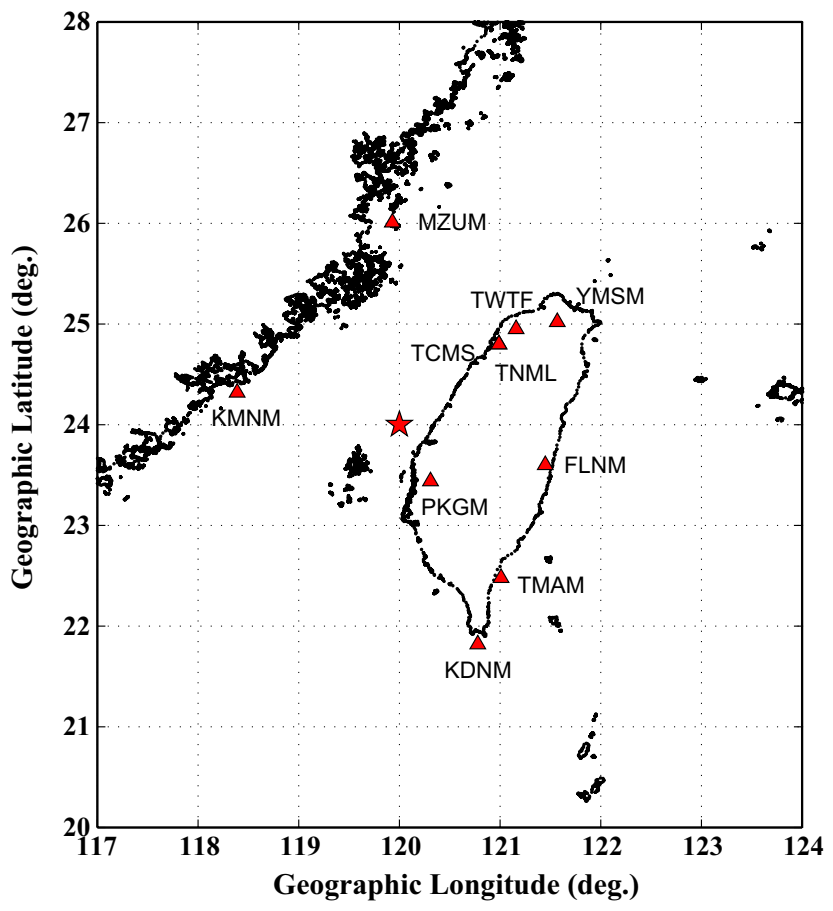

Fig. 1. GPS receivers in the Taiwan area. Red triangles and red star denote the locations of GPS receivers and the place where the TEC models are constructed (24 N $120 \mathrm{E})$, respectively.

with the earthquakes. Recently, this shortcoming of IRI has been improved in the version of 2007 (IRI2007) by applying "NeQuick" (Coïsson et al., 2008a) which based on DGR "profiler" (Di Giovanni and Radicella, 1990). Compared to IRI2001, IRI2007-NeQuick option improved the estimate of TEC (Coïsson et al., 2008b).

In this paper, we construct empirical models of TEC based on functional fitting over the Taiwan area with several parameters of the solar activity. We also construct other empirical models based on median values to compare accuracies of the models. While our models have been constructed to investigate the ionospheric perturbation associated with the large earthquakes, since a regional empirical model has not been constructed yet in the place where TEC variation is large due to ionospheric equatorial anomaly such as the Taiwan area, comparisons of our models with IRI2007 will contribute to improve IRI.

\section{Total Electron Content using the Global Positioning System}

The GPS provides an ideal tool for monitoring temporal and spatial variations of ionospheric electron densities. Many authors (Sardon et al., 1994; Leick, 1995; Liu et al., 1996) evaluated the ionospheric TEC with measurements of modulations on carrier phases and phase codes recorded by dualfrequency ( $\mathrm{f} 1=1575.42 \mathrm{MHz}$ and $\mathrm{f} 2=1227.60 \mathrm{MHz}$ ) GPS re-
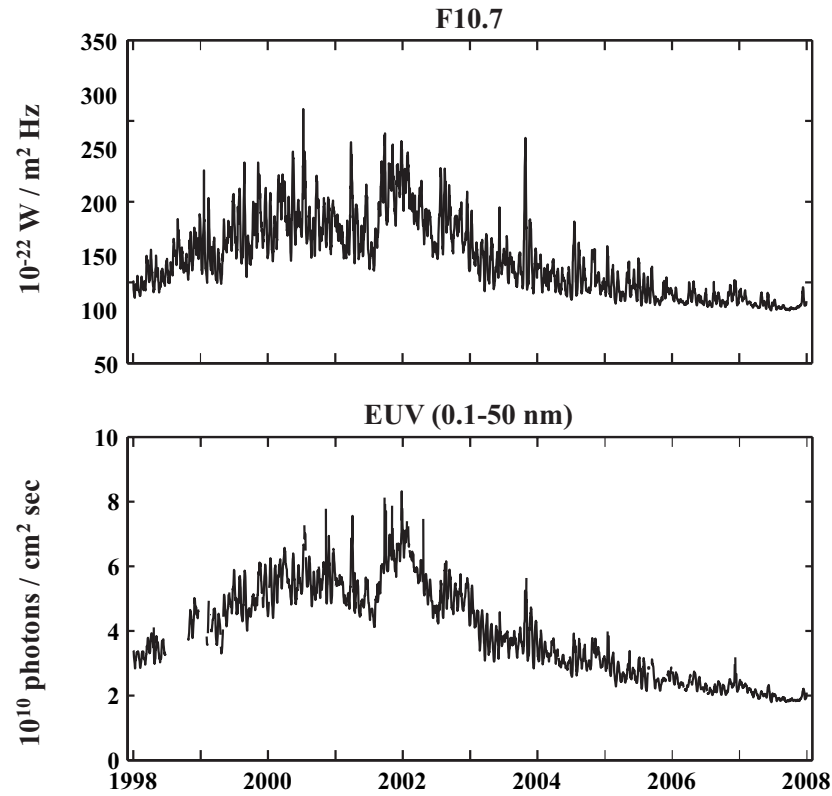

Fig. 2. Time series of F10.7 and EUV fluxes at $0.1-50 \mathrm{~nm}$ obtained by SOHO. EUV have been adjusted to the sun-earth distance. Spike-like sudden enhancements of EUV have been removed.

ceivers. However, instrumental biases are different for the dual-frequencies by each GPS receiver, which produces systematic errors in the estimates of TEC. In order to remove the instrumental biases, in this paper, the Global Ionospheric Map (GIM) developed by the Jet Propulsion Laboratory (Mannucci et al., 1998) is used as a reference to define the biases. The GIM TEC are routinely constructed and published in a 2-h interval by using GPS signals, which are obtained by 1000 s of worldwide ground-based receivers. Note that the spatial resolutions of the GIM on the $\pm 87.5^{\circ}$ latitude and $\pm 180^{\circ}$ longitude are $2.5^{\circ}$ and $5^{\circ}$, respectively. Therefore, we can obtain the instantaneous "snapshot" of the global TEC distribution in spatial and diurnal TEC variation at fixed location. According to Bilitza (2001), the minimum TEC in a day appears around 04:00-06:00 local time. Hence the differential instrumental biases of GPS receivers in the Taiwan area are determined by the minimum TEC value at 04:00 06:00 local time which are calculated by GIM at the place where GPS receivers are situated.

Combining all the data recorded by the GPS network in the Taiwan area (Fig. 1), the diurnal variation of TEC is examined, and then the latitude/longitude map of TEC over the Taiwan area is constructed. An elevation cut-off angle of each GPS receiver is 20 degrees. In order to investigate the daily TEC variations around the Taiwan area, the median value of TEC within $120^{\circ} \mathrm{E}$ and $23^{\circ} \mathrm{N}-25^{\circ} \mathrm{N}$, where the data are the densest, are calculated, and taken the $1.25 \mathrm{~h}$ running mean with 15 min time resolution to eliminate high frequent variations. The values of TEC from 1998 to 2007 are used to construct the models. 


\section{The solar activity}

Variations of observed solar radio noise $10.7 \mathrm{~cm}$, socalled F10.7, which are released on National Geophysical Data Center (http://www.ngdc.noaa.gov/stp/SOLAR/ ftpsolarradio.html), is displayed in the top panel of Fig. 2. F10.7 gradually increased and showed the first peak around January 2000. F10.7 reduced toward the end of 2001, and then suddenly increased again and took the second peak around August 2001. After the second peak, F10.7 showed a continuous reduction toward the end of 2007. The range of F10.7 was between 65.0 and 314.6 during 1998-2007.

Daily EUV $(0.1-50 \mathrm{~nm})$ obtained by the Solar Heliospheric Observatory (SOHO) (Judge et al., 1998) are released on web site of Space Science Center in University of Southern California (http://www.usc.edu/dept/space_ science/). Since the released EUV fluxes are adjusted to the flux at $1 \mathrm{AU}$, the released EUV fluxes are modified by using the sun-earth distance. Intensive spike-like enhancements in daily EUV, which exceeded almost one order of prior day's intensity, were sometimes observed when many invasive flares occurred in one day. The modified EUV which are excluded sudden enhancements are shown in the bottom panel of Fig. 2. The variation of EUV is similar to F10.7 variation, which can be seen the double peaks during the solar maximum.

Here, indicators for the solar activity, $F$, are defined as follows:

$$
\begin{aligned}
& F_{x d c}=(\mathrm{F} 107 \mathrm{C}+\mathrm{F} 107 \mathrm{~d}) / 2, \\
& F_{x d p}=(\mathrm{F} 107 \mathrm{P}+\mathrm{F} 107 \mathrm{~d}) / 2, \\
& F_{\mathrm{EUV}}=\mathrm{EUVd},
\end{aligned}
$$

where

$\mathrm{F} 107 \mathrm{C}=\sum_{d=-(x-1) / 2}^{d=(x-1) / 2} \mathrm{~F} 107 \mathrm{~d} / x$,

$$
\mathrm{F} 107 \mathrm{P}=\sum_{d=-x}^{d=-1} \mathrm{~F} 107 \mathrm{~d} / x
$$

respectively. F107d and EUVd are the daily observed F10.7 and the daily modified EUV, respectively. $\mathrm{X}$, which is a length of day, are $1,7,15,27,54,81,108,135$ and 162 days. Namely, F107C and F107P represents centered F10.7 mean of X days and F10.7 mean from 1 to X days before, respectively. SOHO observed two EUV bands, which are 26-34 nm and $0.1-50 \mathrm{~nm}$. These two bands are correlated linearly (Bilitza, 2000; Kane, 2003; Liu et al., 2006b). The most effective EUV band for TEC production is $65-91 \mathrm{~nm}$, which produces $\mathrm{O}^{+}$in $\mathrm{F} 1$ region (Banks and Kockarts, 1973). From comparison of $0.1-50 \mathrm{~nm}$ band intensity with $65-90 \mathrm{~nm}$ band intensity during 1994-2007 reproduced by a solar EUV model (Richards et al., 1994a, b), intensities of these two bands are

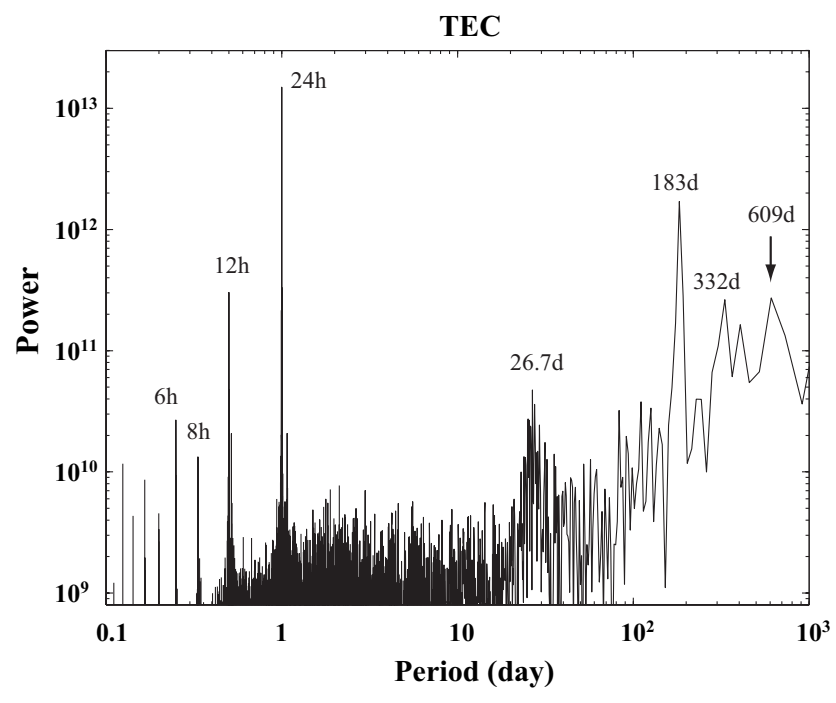

Fig. 3. Power spectrum of TEC variation over the Taiwan area from 1998 to 2007.

hightly correrted (correration coefficient is 0.99 ). Thus, 0.1$50 \mathrm{~nm}$ band is reasonalbe for the parameter of TEC reprodution. The band of EUV flux in $0.1-50 \mathrm{~nm}$ is only used hereafter.

In order to investigate coherence of $F_{\mathrm{EUV}}$ to $F_{x d c}$ and $F_{x d p}$, linear correlation coefficients, $S(x, y)=C(x, y) / \sqrt{C(x, x) C(y, y)}$, where the covariance between data set $\mathrm{x}$ and $\mathrm{y}, C(x, y)=\mu\left[\left(x-\mu_{x}\right)\left(y-\mu_{y}\right)\right]$ and $\mu_{x}$ is the mathematical expectation of $x$, are examined. Though $F_{81 d c}$ has been pointed out as good indicator for EUV (Liu et al., 2006b), correlation between $F_{81 d c}$ and $F_{\text {EUV }}$ does not show the strongest value with 0.981 (see Table 1). The correlation coefficients for $F_{54 d p}, F_{81 d p}$, $F_{108 d p}, F_{108 d c}, F_{135 d c}$ and $F_{162 d c}$ are slightly better than that of $F_{81 d c}$, which are 0.982 .

\section{TEC variation over the Taiwan area}

To determine the functions for the models based on the functional fitting, TEC variations are investigated before the functions are selected. In following subsection, diurnal, seasonal, annual and longer variations are discussed. In addition, responses of TEC with the solar activity are also shown.

\subsection{Diurnal variation}

Figure 3 shows power spectrum of TEC from 1998 to 2007. Periods of $4,8,12$, and $24 \mathrm{~h}$ are clearly seen. Since ionospheric plasma is mainly produce by EUV from the sun, the period of $24 \mathrm{~h}$ is the most dominant. Other periods might come from interaction between neutral atmosphere and ionosphere. Recently, evidences of modulation cased by waves of neutral atmosphere have been found (Sagawa et al., 2005; 
Table 1. The correlation coefficients of $F_{x d p}$ and $F_{x d c}$ with EUV $(0.1-50 \mathrm{~nm})$.

\begin{tabular}{cccccccccc}
\hline & $1 \mathrm{~d}$ & $7 \mathrm{~d}$ & $15 \mathrm{~d}$ & $27 \mathrm{~d}$ & $54 \mathrm{~d}$ & $81 \mathrm{~d}$ & $108 \mathrm{~d}$ & $135 \mathrm{~d}$ & $162 \mathrm{~d}$ \\
\hline$F_{x d p}$ & 0.957 & 0.966 & 0.972 & 0.979 & 0.982 & 0.982 & 0.982 & 0.981 & 0.980 \\
$F_{x d c}$ & 0.954 & 0.960 & 0.968 & 0.973 & 0.978 & 0.981 & 0.982 & 0.982 & 0.982 \\
\hline
\end{tabular}

Table 2. The correlation coefficients between $F$ parameters and TEC in 15:00 LT. The correlation coefficient between $F_{\mathrm{EUV}}$ and the TEC in 15:00 LT is 0.816 .

\begin{tabular}{cccccccccc}
\hline & $1 \mathrm{~d}$ & $7 \mathrm{~d}$ & $15 \mathrm{~d}$ & $27 \mathrm{~d}$ & $54 \mathrm{~d}$ & $81 \mathrm{~d}$ & $108 \mathrm{~d}$ & $135 \mathrm{~d}$ & $162 \mathrm{~d}$ \\
\hline$F_{x d p}$ & 0.776 & 0.791 & 0.801 & 0.804 & 0.809 & 0.809 & 0.809 & 0.809 & 0.808 \\
$F_{x d c}$ & 0.773 & 0.780 & 0.791 & 0.801 & 0.807 & 0.809 & 0.809 & 0.809 & 0.808 \\
\hline
\end{tabular}

Immel et al., 2006; Lin et al., 2007). For instance, eastward tide of wave number 3 is strongly affected equatorial ionosphere via collision between neutral atmosphere and plasma in E-layer. One of the phenomena caused by the interaction between neutral atmosphere and plasma is found in ionospheric EUV emission obtained by the IMAGE satellite (Sagawa et al., 2005; Immel et al., 2006). In addition, similar longitudinal structure of ionospheric plasma density was observed by FORMSAT3/COSMIC (Lin et al., 2007).

\subsection{Seasonal, annual and longer variations}

Since the rotation period of the sun is about 25 days, the synodic period with the earth, which produces F10.7 variation, is about 27 days. Therefore, the power spectrum has peak power in 26.7 days period. In $F$ region, where peak plasma density is observed, production rate of plasma is dominated by density of $\mathrm{O}$ due to direct photo ionization of $\mathrm{O}$ and recombination rate is dominated by density of $\mathrm{N}_{2}$ due to recombination of $\mathrm{O}^{+}$and $\mathrm{N}_{2}$. The density variations of $\mathrm{O}$ and $\mathrm{N}_{2}$, which have two maximums per year in March and September, produce the semiannual variation of TEC, whose period is 183 days. Density of F region is also affected by neutral wind in thermosphere (Oyama et al., 1996). The seasonal variation of the neutral wind also produces the seasonal variation of TEC. The power spectrum shows annual (332 day) and longer variations (609 day). Existence of the equatorial quasi-biennial oscillation (QBO) in stratosphere, whose period is approximately 28 months, is widely known (Baldwin et al., 2001). Since a troposphere-thermosphere coupling has been pointed out (Forbes et al., 2006), QBO might affect variation of plasma in the ionosphere. As the result of the coupling, longer variation of TEC whose period is 609 days might be produced. Coupling between ionospheric plasma and QBO will be studied in near future.

\subsection{Response of TEC to the solar activity indexes, $F$}

In order to study responses of TEC to the solar activity indexes $F$ which was defined in Sect. 3, the correlation coefficients between $F$ and TEC in 15:00 LT (TEC 15 LT), which usually show daily maximum, during geomagnetic condition $\left(D_{s t}>-30 \mathrm{nT}\right)$ are examined (Table 2$)$. The correlation coefficient between $F_{\text {EUV }}$ and the TEC $_{15}$ LT shows the strongest value with 0.816 . This result is no wonder because EUV is a primary source for ionospheric plasma above D-region (Bilitza, 2000) and F1 region (Banks and Kockarts, 1973). $F_{x d p}$ are better than $F_{x d c}$ for indicator of TEC $15 \mathrm{LT}$ when the same day lengths are compared. Although the sudden enhancements of EUV have been excluded in our analysis (the bottom panel of Fig. 2), if all EUV data are used for the analysis, a correlation coefficient between EUV and TEC $_{15 \mathrm{LT}}$ (0.645) becomes weaker than the other coefficients. This fact suggests that TEC does not enhance linearly anymore when large flares frequently occurred. Seasonal variations of TEC $_{15 \text { LT }}$ with $F_{1 d c}$ parameter are illustrated in Fig. 4 . The variations of $\mathrm{TEC}_{15 \mathrm{LT}}$ are saturated over F10.7=200 except September equinox. Clear saturation of $\mathrm{TEC}_{15 \mathrm{LT}}$ cannot be seen during September equinox. TEC 15 LT over F10.7=250 in September equinox were observed September and October 2001. More than 10 geomagnetic storms occurred during this period. Large-scale equatorward moving gravity waves induced by Joule heating of auroral electro jet propagate during the geomagnetic storm (Richimond, 1978; Fujiwara et al., 1996). The equatorward wind arising from the gravity waves lifts plasma up in middle latitude, and then TEC enhance during the geomagnetic storm (Shiokawa et al., 2002). Although the data were selected during $D_{s t}>-30 \mathrm{nT}$, the frequent geomagnetic storms might affect ionosphere distribution longer than usual. Therefore $\mathrm{TEC}_{15 \mathrm{LT}}$ show such high values and the saturation might not be seen in September equinox in our study. 

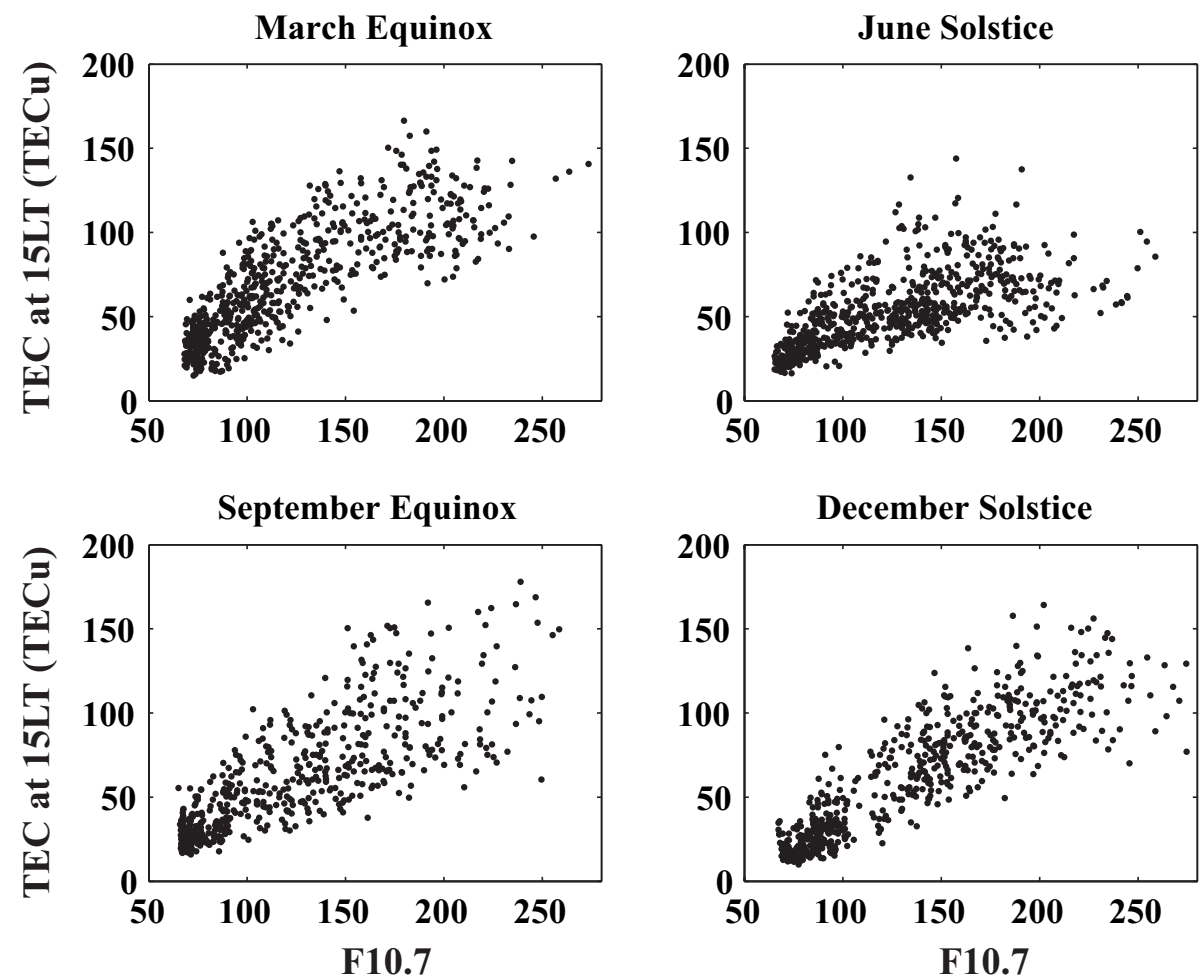

Fig. 4. TEC variation of 15:00 LT with daily F10.7 during the geomagnetic quiet condition $\left(D_{s t}>-30\right)$.

\section{Methodology}

Methodology of constructing empirical models based on the functional fitting is shown in following subsection. For comparison, we also construct other empirical models based on the median values, which is also described in following subsection. Both of the models are calculated TEC as functions for 3 parameters which are local time (LT), day of year (DOY) and the solar activity parameters $F$ which are defined in the Sect. 4. TEC observed over the Taiwan area $\left(120^{\circ} \mathrm{E}, 24^{\circ} \mathrm{N}\right)$ from 1998 to 2007 during the geomagnetic quiet condition $\left(D_{s t}>-30\right)$ are used to construct the both models. These data are not included whole of 11 year's solar cycle but include the solar maximum and minimum conditions (Fig. 2).

\subsection{The empirical model based on the functional fitting}

The methodology of constructing empirical models based on the functional fitting, which has been originally applied and succeed to construct an empirical model of $\mathrm{O}^{+}-\mathrm{H}^{+}$transition height based on topside sounder data (Marinov et al., 2004), shown here. As shown in the previous section, since the variation of TEC with the solar activity show the saturation, cubic function or more high order function should be applied as the function for $F$ parameters to reproduce the variation. Wave number 2 is required for seasonal (DOY) variation at least and wave number 4 is required for LT variation. As the result of trial and error, the cubic function for $F$ parameters, wave number 3 for the seasonal variation and wave number 4 for LT variation are applied to the functional models. The functions for each variation are defined as follows:

$$
\begin{gathered}
\begin{aligned}
f(F)= & a_{1}+a_{2} F+a_{3} F^{2}+a_{4} F^{3} \\
= & a_{1} f_{1}^{\prime}+a_{2} f_{2}^{\prime}+a_{3} f_{3}^{\prime}+a_{4} f_{4}^{\prime},
\end{aligned} \\
\begin{aligned}
g(\mathrm{DOY}) & =b_{1}+\sum_{i=1}^{3}\left(b_{2 i} \cos 2 \pi i \cdot \mathrm{DOY}+b_{2 i+1} \sin 2 \pi i \cdot \mathrm{DOY}\right) \\
& =b_{1} g_{1}^{\prime}+\cdots+b_{7} g_{7}^{\prime},
\end{aligned} \\
h(\mathrm{LT})=c_{1}+\sum_{i=1}^{4}\left(c_{2 i} \cos \frac{\pi i \cdot \mathrm{LT}}{12}+c_{2 i+1} \sin \frac{\pi i \cdot \mathrm{LT}}{12}\right) \\
=c_{1} h_{1}^{\prime}+\cdots+c_{9} h_{9}^{\prime},
\end{gathered}
$$

where $a, b, c$ are coefficient for fitting and detail description of functions $f^{\prime}, g^{\prime}$, and $h^{\prime}$ are displayed in Appendix A. DOY is normalized by the length of the year. Function reproducing TEC value is assumed as multiplication of these 3 functions. Then we can obtain:

$$
\begin{aligned}
\operatorname{TEC}(F, \mathrm{DOY}, \mathrm{LT}) & =f(F) \cdot g(\mathrm{DOY}) \cdot h(\mathrm{LT}) \\
& =\sum_{i, j, k} a_{i} f_{i}^{\prime} \cdot b_{j} g_{j}^{\prime} \cdot c_{k} h_{k}^{\prime} \\
& =\sum_{n=1}^{252} \alpha_{n} \mathrm{TEC}_{n}^{\prime},
\end{aligned}
$$


Table 3. Bin ranges for $F$ parameter: $\mathrm{A}=[60,80,120,160,210,300], \mathrm{B}=[60,80,120,150,200,240] ; \mathrm{EUV}=[1.8,2.3,3,4,5,6.5]$ $\left(\times 10^{10}\right.$ photons $\left./ \mathrm{cm}^{2} \mathrm{~s}\right)$.

\begin{tabular}{cccccccccc}
\hline Model & $1 \mathrm{~d}$ & $7 \mathrm{~d}$ & $17 \mathrm{~d}$ & $27 \mathrm{~d}$ & $54 \mathrm{~d}$ & $81 \mathrm{~d}$ & $108 \mathrm{~d}$ & $135 \mathrm{~d}$ & $162 \mathrm{~d}$ \\
\hline Centered F10.7 & A & A & A & A & B & B & B & B & B \\
Previous F10.7 & A & A & A & B & B & B & B & B & B \\
\hline
\end{tabular}

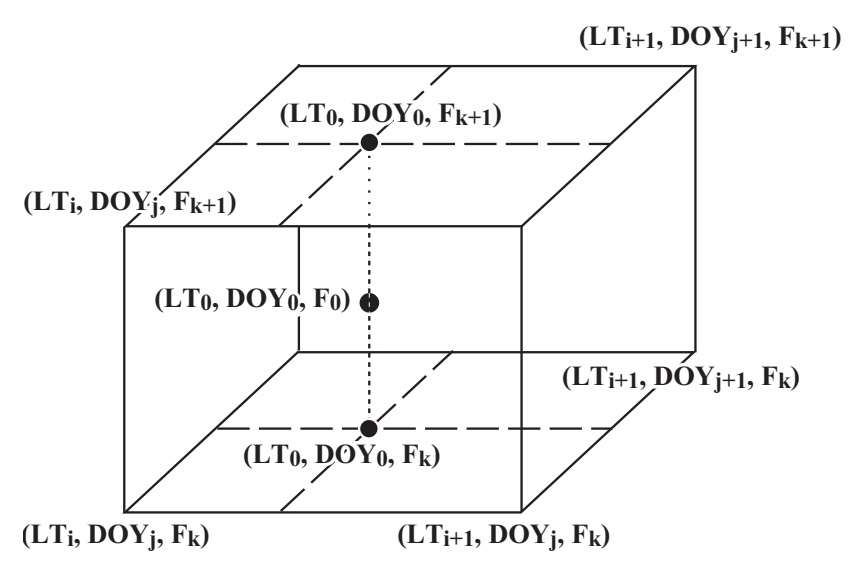

Fig. 5. The methodology of constructing the median models. $\mathrm{LT}_{i}$, DOY $_{j}, F_{k}$ denote the location of local time (LT), day of year (DOY), the solar activity $(F)$ in $(i, j, k)$-th bin. The model values are calculated by cubic spline interpolation in LT-DOY space and by linear interpolation in $\mathrm{F}$ space.

where $\quad n=(i-1) \times 63+(j-1) \times 9+k, \quad i=1, \cdots, 4$, $j=1, \cdots, 7, k=1, \cdots, 9$. In order to calculate coefficient $\alpha$, more than 252 data are needed. The $\alpha$ can be obtained by ciphering following normal-equation matrix:

$$
\begin{aligned}
& \left(\begin{array}{c}
\sum \mathrm{TEC} \cdot \mathrm{TEC}_{1}^{\prime} \\
\vdots \\
\sum \mathrm{TEC} \cdot \mathrm{TEC}_{252}^{\prime}
\end{array}\right)= \\
& \left(\begin{array}{ccc}
\sum \mathrm{TEC}_{1}^{\prime} \cdot \mathrm{TEC}_{1}^{\prime} & \cdots & \sum \mathrm{TEC}_{1}^{\prime} \cdot \mathrm{TEC}_{252}^{\prime} \\
\vdots & \ddots & \vdots \\
\sum \mathrm{TEC}_{252}^{\prime} \cdot \mathrm{TEC}_{1}^{\prime} & \cdots & \sum \mathrm{TEC}_{252}^{\prime} \cdot \mathrm{TEC}_{252}^{\prime}
\end{array}\right)\left(\begin{array}{c}
\alpha_{1} \\
\vdots \\
\alpha_{252}
\end{array}\right)
\end{aligned}
$$

Several $F$ are applied to develop the models, $F_{x d c}$ functional model, $F_{x d p}$ functional model and $F_{\mathrm{EUV}}$ function model. The values of coefficients $\alpha$ for $F_{\mathrm{EUV}}$ functional model, which is the most accurate model as discussed later, are shown in Appendix B.

\subsection{The empirical model based on the median values}

The methodology of constructing the empirical models based on the median values is described here. In order to investigate response of TEC to the solar activities, several $F$ parameters are applied to develop the models, $F_{x d c}$ median model,
$F_{x d p}$ median model and $F_{\text {EUV }}$ median model. Three steps are taken to construct the models. First of all, bins are set in LT with $1 \mathrm{~h}$ resolution (24 nodes), DOY normalized by a length of the year with $1 / 12$ resolution (12 nodes) and $F$ space (5 nodes). The ranges of $F$ are chosen as displayed in Table 3. The median values are calculated in each bin $\left(\mathrm{LT}_{i}, \mathrm{DOY}_{j}, F_{k}\right)$, where $\mathrm{LT}_{i}, \mathrm{DOY}_{j}, F_{k}$ denote the location of LT, DOY, $F$ in $(i, j, k)$-th bin and all median values are stored in a file. In second step, to calculate TEC at $\left(\mathrm{LT}_{0}, \mathrm{DOY}_{0}, F_{0}\right)$, TEC at $\left(\mathrm{LT}_{0}, \mathrm{DOY}_{0}, F_{k}\right)$ and $\left(\mathrm{LT}_{0}, \mathrm{DOY}_{0}\right.$, $\left.F_{k+1}\right)$ are interporated using the cubic spline function in LTDOY space from surrounding bins, where $\mathrm{LT}_{i}<\mathrm{LT}_{0}<\mathrm{LT}_{i+1}$, DOY $_{j}<\mathrm{DOY}_{0}<\mathrm{DOY}_{j+1}$ and $F_{k}<F_{0}<F_{k+1}$, respectively (also see Fig. 5). Finally, TEC at $\left(\mathrm{LT}_{0}, \mathrm{DOY}_{0}, F_{0}\right)$ is interporated by linear function in $\mathrm{F}$ space with $\left(\mathrm{LT}_{0}, \mathrm{DOY}_{0}\right.$, $\left.F_{k}\right)$ and $\left(\mathrm{LT}_{0}, \mathrm{DOY}_{0}, F_{k+1}\right)$.

\section{Model results and discussions}

\subsection{Time series of observed TEC, the 15-days running median, the function model and IRI2007}

The TEC reproduced by the $F_{\mathrm{EUV}}$ functional model are compared with the observed TEC, the 15-days running median and IRI2007 together with Dst and daily EUV (Fig. 6). During August 2002, two magnetic storms occurred around 2nd and 19th. Minimum Dst of the both storms were -96 nT. Daily EUV shows periodic variation, which increase from local minimal values of $2.2 \times 10^{10}$ on 8 th to local maximal value of $3.0 \times 10^{10}$ on 19 th and decreace to $2.3 \times 10^{10}$ photos $/ \mathrm{cm}^{2} \mathrm{~s}$ on 27 th. IRI2007 are in good agreement with the observed TEC from 23rd to the end of August, but obviously overestimate the observed TEC from 2nd to 12 th. On the other hand, although the 15-days running median are in good agreement with the observed TEC from 2nd to 12 th, the 15 -days running median underestimate the observed TEC from 13th to 23rd. These disagreements come from rapid variation of daily EUV during 8th to 27 th. The 15-days running median cannot clearly follow this kind of rapid F10.7 variation. In contrast, the $F_{\text {EUV }}$ function model is in very good agreement with the observed TEC except periods of the geomagnetic storm. Since our models are constructed by the data without the geomagnetic storms, our models only reproduce TEC during the quiet geomagnetic 

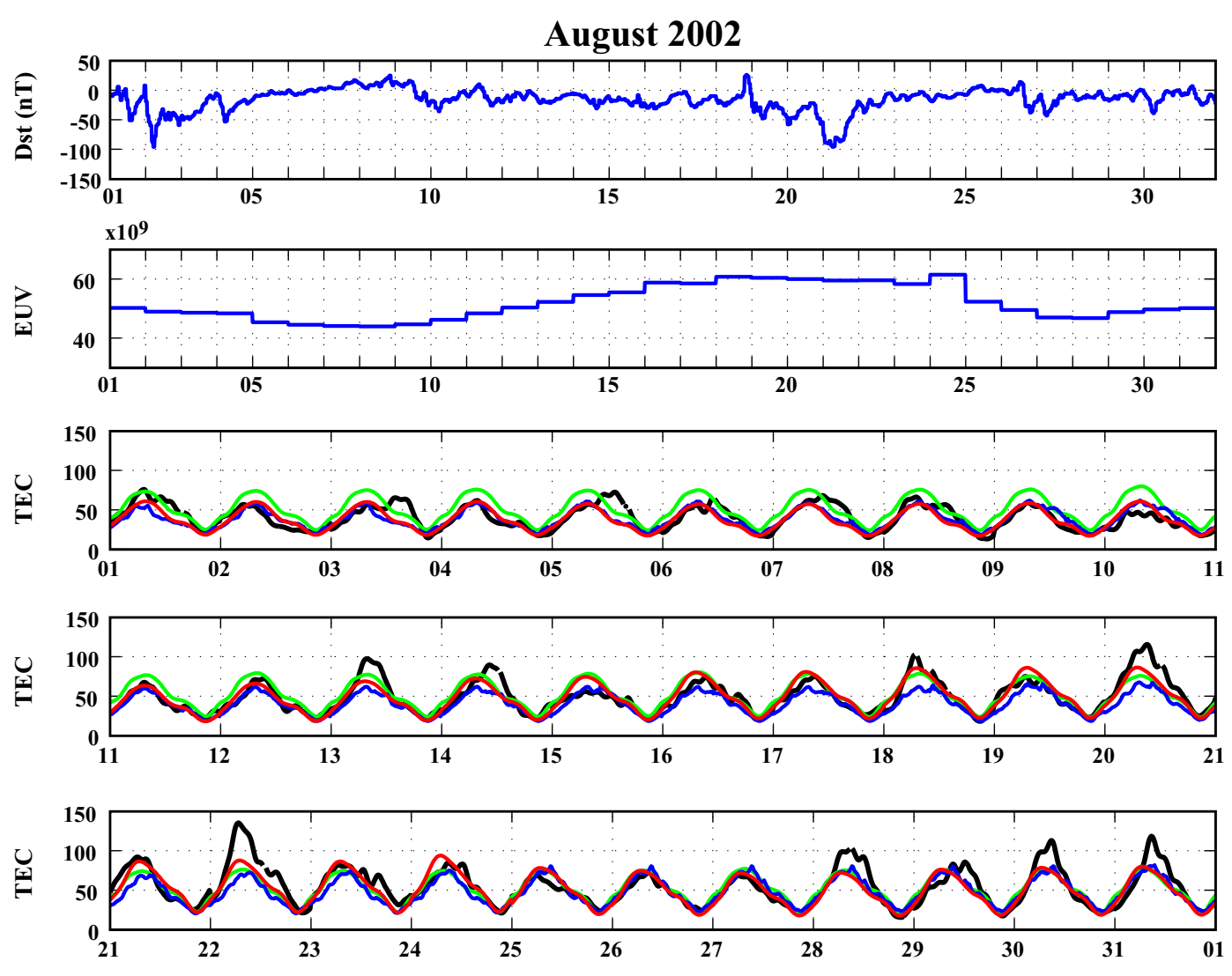

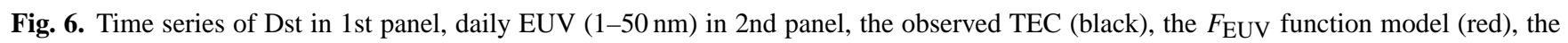
15-days running median (blue) and IRI2007 (green) in the bottom 3 panels during August 2002.

condition. In other ward, our models are good references for comparing the quiet to the disturbed ionosphere. Thus the enhancement of the observed TEC around 20th indicates an effect of the magnetic storm by the comparison of the observed TEC with the $F_{\mathrm{EUV}}$ functional model. When duration of the geomagnetic storm is long enough, the 15-days running median is contaminated by the magnetic storm effect itself. In such case, the 15-days running median cannot be referred as quiet ionosphere any more. This is another shortcoming of the 15-days running median.

\subsection{Root mean square errors of the models}

In order to estimate accuracies of the models, root mean square error (RMS), which is widely used to evaluate the model error (Kutiev and Marinov, 2007; Habarulema et al., 2007), is calculated as follows:

$\mathrm{RMS}=\sqrt{\frac{1}{n} \sum_{i=1}^{n}\left(o_{i}-m_{i}\right)^{2}}$,

where $o_{i}, m_{i}$ and $n$ denote the observed TEC, the modeled TEC and total number of the data, respectively. Figure 7 illustrates RMSs for the 15-days running median (green triangle), the functional models (inverted triangle) and the me- dian models (square) during the geomagnetic quiet condition, respectively. Colors of each mark display difference of the solar flux indicators; blue, red and yellow denote $F_{x d p}, F_{x d c}$ and $F_{\mathrm{EUV}}$, respectively. Lengths of $\mathrm{X}$ days are shown in the horizontal axis. RMS of IRI2007 is $14.3 \mathrm{TECu}$, which is the biggest RMS value among all models. $F_{\mathrm{EUV}}$ is the most competent parameter for the empirical models. The $F_{\mathrm{EUV}}$ functional model shows the lowest RMS with $9.15 \mathrm{TECu}$. The $F_{\text {EUV }}$ median model also shows the lowest RMS among the median models. These results are consequential because EUV radiations are the primary source for ionospheric plasma above D-region (Bilitza, 2000) and F1 region (Banks and Kockarts, 1973). Comparing with the same $\mathrm{X}$ days of $\mathrm{F}$, the functional models show better accuracy than those of the median models. Though RMSs for the both two type of the models using $F_{1 d p}$ and $F_{1 d c}$ are similar 15-days running median, RMSs gradually decrease as the length of $\mathrm{X}$ days increase. The $F_{54 d p}$ functional model exhibits the minimum RMS with 9.38 TECu among the all models using F10.7. The $F_{54 d p}$ median model presents the best accuracy with $9.43 \mathrm{TECu}$ among median models using F10.7. When longer $X$ days are applied, accuracies of the model using F10.7 get worse again. 


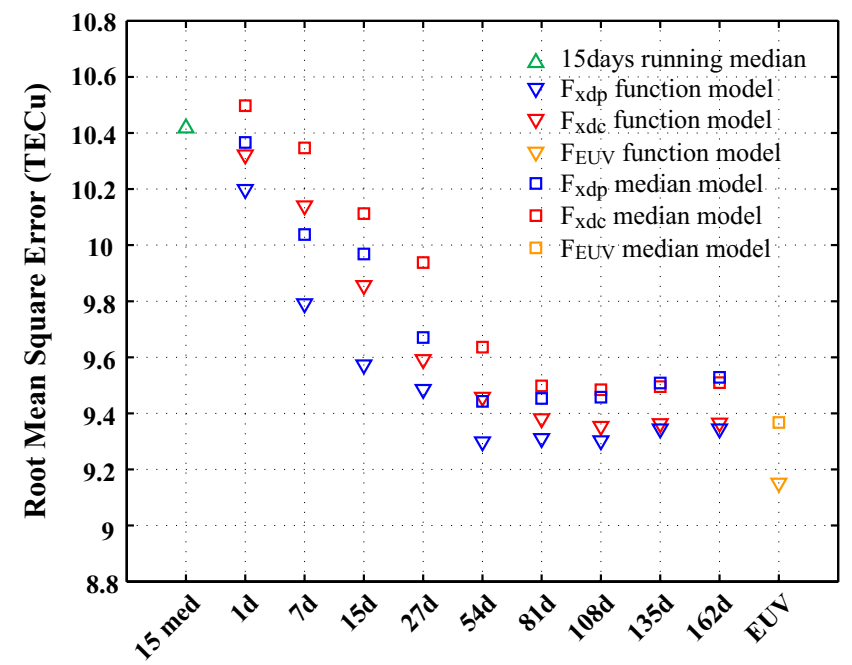

Fig. 7. Root mean square errors for the models. Marks show difference of the models types and colors show difference of $\mathrm{F}$ parameters. Namely, the 15-days running median (green triangle), the $F_{x d p}$ functional model (blue inversed triangle), the $F_{x d c}$ functional model (red inversed triangle), the $F_{\mathrm{EUV}}$ functional model (yellow inversed triangle), the $F_{x d p}$ median model (blue square), the $F_{x d c}$ median model (red square), and $F_{\text {EUV }}$ median model (yellow square), respectively. Labels of $\mathrm{X}$ axis indicate the average lengths of F10.7.

\subsection{Root mean square errors of the models for each year}

RMSs are examined year by year to investigate difference of accuracies related to deference of the solar activity (Fig. 8). RMSs of the $F_{\text {EUV }}$ functional model are more preferable than the 15-days running median and IRI2007 in all years. RMSs for the $F_{\mathrm{EUV}}$ function model and the 15-days running median become larger during the high solar activity and small during the low solar activity because RMS roughly correlates with the intensity of TEC. Differences of RMSs between the $F_{\text {EUV }}$ functional model and the 15-days running median during the high solar activity are much larger than during the low solar activity. Response to the solar activity variation of the 15days running median is much worse than that of the $F_{\mathrm{EUV}}$ functional model as shown in Fig. 7. Hence RMSs of the 15days running median get worse during the high solar activity, which highly fluctuate, than the low solar activity. On the other hand, RMSs of IRI2007 are much larger than the others during the both high and low solar activity. IRI2007 can only reproduce TEC equivalently to the others during 1998-1999 and 2004-2005, which is the moderate solar activity. The reason why RMSs are large during the low and high solar activity arises from reproducibility of the solar flux variation as discussed later (the bottom panel of Fig. 10).

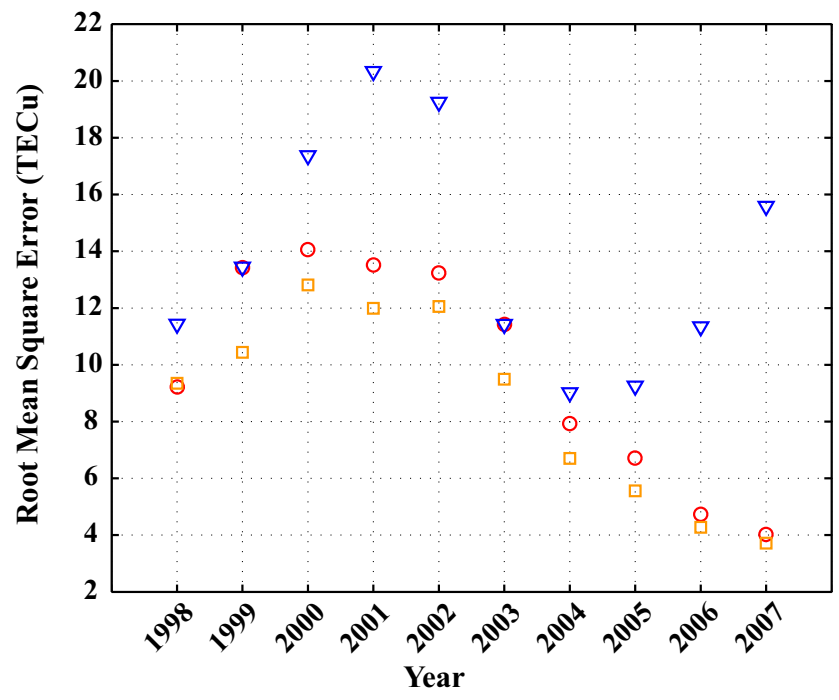

Fig. 8. Root mean square errors of IRI2007 (blue inversed triangle), the 15-days running median (red circle) and the $F_{\mathrm{EUV}}$ functional model (orange square) for each year from 1998 to 2007.

\subsection{Comparison of the $F_{\mathrm{EUV}}$ functional model with IRI2007}

LT, DOY, and the solar flux variations of the $F_{\mathrm{EUV}}$ functional model are investigated (Fig. 9). The medians of the ratio are between 0.96 and 1.01 in LT variation (the top panel of Fig. 9). The minimum and maximum median appear in 05:00 and 03:00 LT, where observed TEC are smaller than the daytime. Errors in the night time are also larger than that in the daytime. The $F_{\text {EUV }}$ median model also shows good agreement with observations in DOY variation (middle panel of Fig. 9). The medians of the ratio are seen between 0.97 and 1.01. When $F_{\text {EUV }}$ is over $7.5 \times 10^{10}$ photon $/ \mathrm{cm}^{2}$ s, the $F_{\text {EUV }}$ functional model slightly overestimates the observed TEC. The median of the ratio is 0.93 .

Meanwhile, IRI2007 has large deviations to the observed TEC (Fig. 10). IRI2007 overestimates the observed TEC except 04:00 LT as illustrated in the top panel of Fig. 11. The medians of the ratio in LT variation are between 0.77 and 1.02. Regarding DOY variation, IRI2007 overestimates the observed TEC around June solstice. Particularly, IRI2007 largely overestimates the observed TEC in July. The median of the ratio is 0.80 in June. In addition, when $F_{\mathrm{EUV}}$ is below $3.0 \times 10^{10}$ photon $/ \mathrm{cm}^{2} \mathrm{~s}$, IRI2007 overestimates the observed TEC with decreasing $F_{\text {EUV }}$. Moreover, IRI2007 underestimates when $F_{\mathrm{EUV}}$ is over $6.0 \times 10^{10}$ photon $/ \mathrm{cm}^{2} \mathrm{~s}$. The median of the ratio reaches 1.2 in the case that $\mathrm{F}$ is $7.0 \times 10^{10}$ photon $/ \mathrm{cm}^{2} \mathrm{~s}$.

Comparing Figs. 9 to 10, the $F_{\mathrm{EUV}}$ functional model obviously reproduces TEC much better than IRI2007. On the other hand, IRI2007 presents better reproductions between $3.5-5.0 \times 10^{10}$ photon $/ \mathrm{cm}^{2} \mathrm{~s}$, which is the moderate 

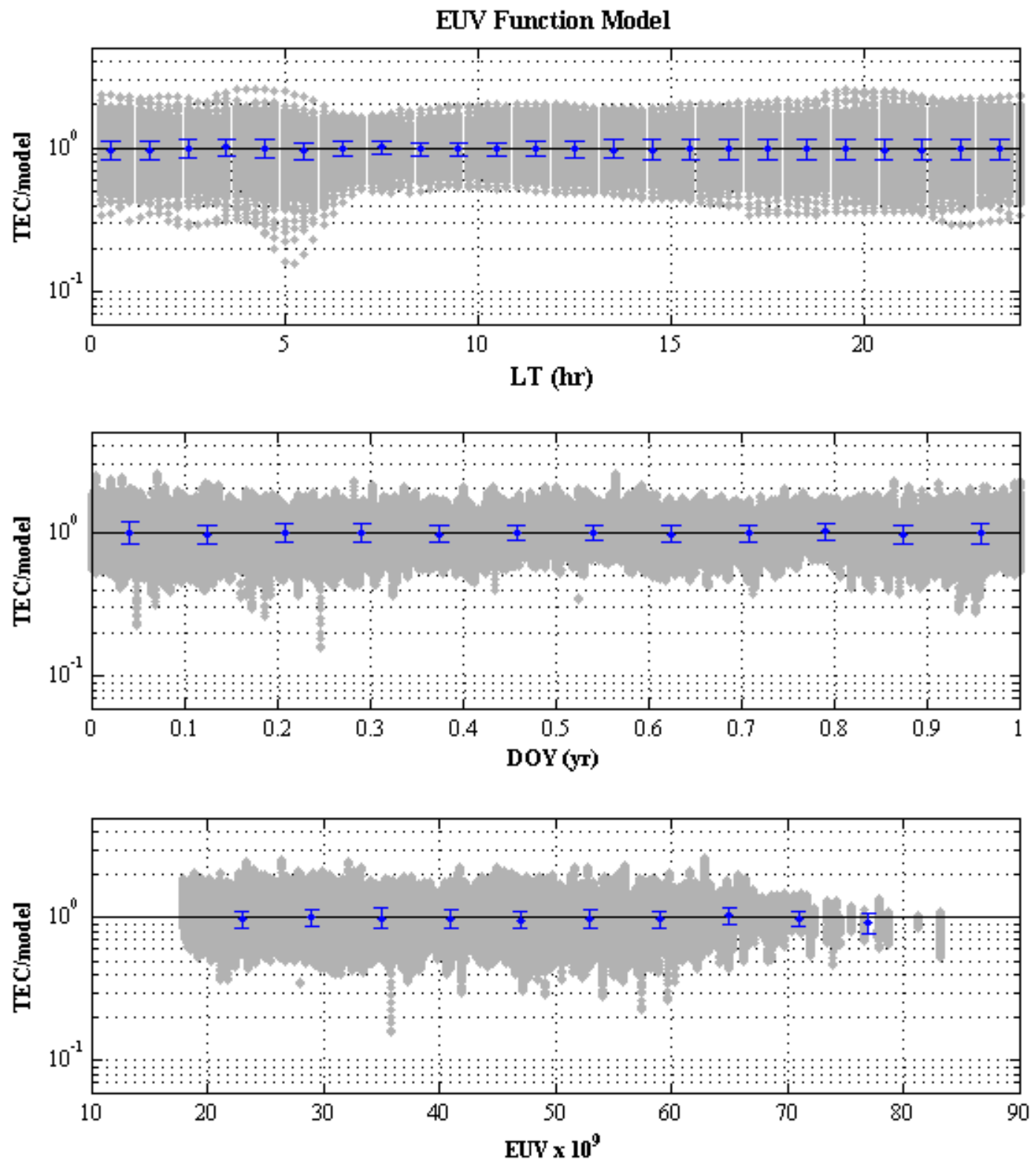

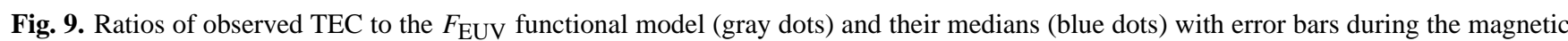
quiet condition $\left(D_{s t}>-30 \mathrm{nT}\right)$.

solar activity. This is the reason why RMSs of IRI2007 is comparable to the $F_{\mathrm{EUV}}$ function model and the 15-days running median during 1998-1999 and 2003-2004 (Fig. 8).

Comparison of RMS also indicates primacy of the $F_{\mathrm{EUV}}$ function model over IRI2007 (Fig. 11). RMSs of the $F_{\mathrm{EUV}}$ function model are always less than IRI2007 in any LT, DOY and EUV. Differences of RMS become large during daytime, equinoxes. Especially, the differences of RMS become large when the solar activity is high and low.

\section{Concluding remarks}

We constructed the empirical models of TEC based on median values and the functional fitting over the Taiwan area $\left(120^{\circ} \mathrm{E}, 24^{\circ} \mathrm{N}\right)$ during geomagnetically quiet condition. The models provide TEC as functions of day of local time (LT), year (DOY) and several solar fluxes $(F)$. This paper is for the first time comparing the median based model with the functional fitting model. Results indicate the functional fitting model yielding a better performance than the median based one. Meanwhile we find that the EUV radiation is essential to derive an optimal TEC. The $F_{\mathrm{EUV}}$ functional model can 

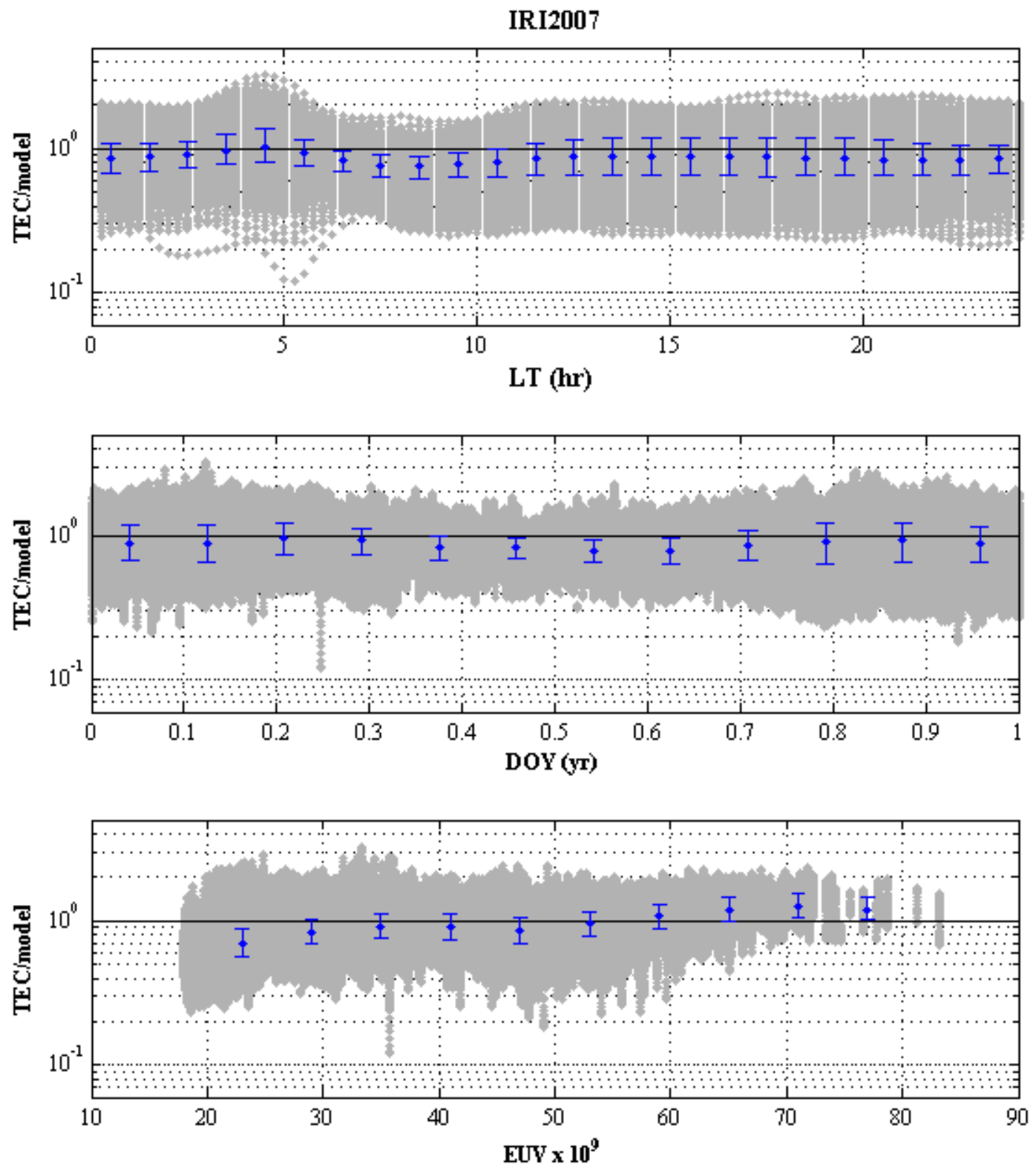

Fig. 10. Same as Fig. 10, but for IRI2007.

produce TEC the most accurately. Many authors have applied $F_{81 d c}$ as the indicator for EUV. However, our results suggest that $F_{54 d p}$ is better than $F_{81 d c}$ as the indicator not only for EUV but also for TEC over the Taiwan area. $F_{\mathrm{EUV}}$ is the best parameter under the quiet condition, but we must note that $F_{\mathrm{EUV}}$ cannot be used for the indicator of TEC when EUV is highly fluctuating due to the intensive flares. The 15days running median is accurate as well as the $F_{\mathrm{EUV}}$ function model during the low solar activity. However, the 15-days running median get worse during the high solar activity as compared with the $F_{\mathrm{EUV}}$ functional model.

Though IRI2007 has been improved in the upper ionosphere from IRI2000, IRI2007 has still shortcoming in LT, DOY, and the solar activity variations. Especially, IRI2007 overestimates when the solar activity is low, and underestimates when the solar activity is high.

Our models can only reproduce TEC during the quiet magnetic condition. Comparing our models to observations during disturbed conditions, we can investigate effects which produced by the magnetic storms and the other phenomena, such as the earthquakes. Our model will be improved to add a storm time option in near future. Although the models have been constructed to achieve to detect the ionospheric perturbations associated with the large earthquakes, because regional empirical model in the place where the equatorial ionospheric anomaly is observed has not been constructed yet, our models must contribute to improve IRI. 


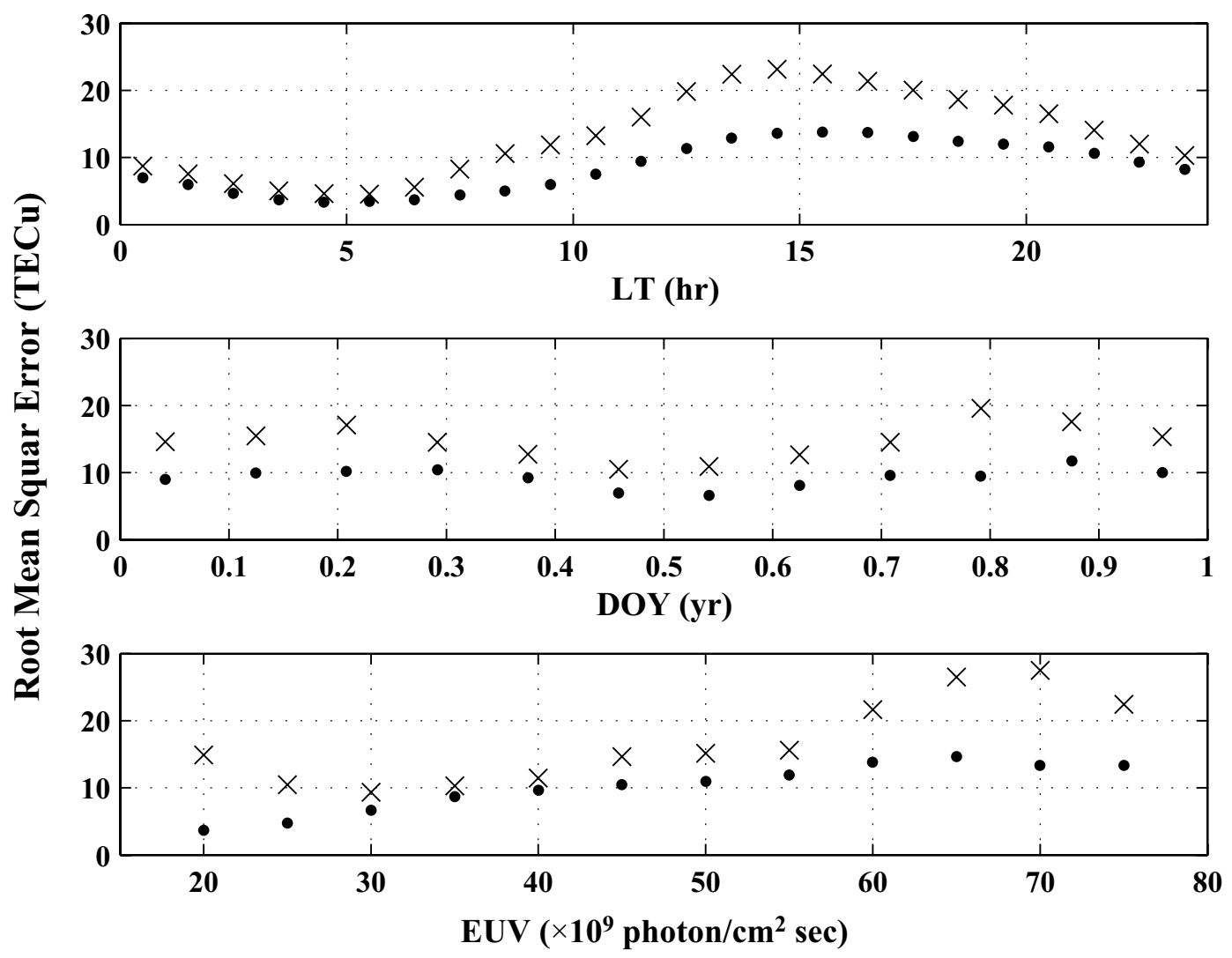

Fig. 11. Comparison of $F_{\mathrm{EUV}}$ functional model with IRI2007. Dots and crosses denote root mean square errors of $F_{\mathrm{EUV}}$ functional model and IRI2007, respectively.

\section{Appendix A}

\section{Applied functions}

Applied functions $f^{\prime}, g^{\prime}$, and $h^{\prime}$ are defined as follows:

$f_{1}^{\prime}=1$,

(A1)

$f_{2}^{\prime}=F$,

$f_{3}^{\prime}=F^{2}$

$f_{4}^{\prime}=F^{3}$

$g_{1}^{\prime}=1$

$g_{2}^{\prime}=\cos (2 \pi \cdot \mathrm{DOY})$,

$g_{3}^{\prime}=\sin (2 \pi \cdot \mathrm{DOY})$,

$g_{4}^{\prime}=\cos (4 \pi \cdot \mathrm{DOY})$,

$g_{5}^{\prime}=\sin (4 \pi \cdot \mathrm{DOY})$,

$g_{6}^{\prime}=\cos (6 \pi \cdot \mathrm{DOY})$,

$g_{7}^{\prime}=\sin (6 \pi \cdot \mathrm{DOY})$, $h_{1}^{\prime}=1$,

$h_{2}^{\prime}=\cos (\pi \cdot \mathrm{LT} / 12)$,

$h_{3}^{\prime}=\sin (\pi \cdot \mathrm{LT} / 12)$,

$h_{4}^{\prime}=\cos (\pi \cdot \mathrm{LT} / 6)$,

$h_{5}^{\prime}=\sin (\pi \cdot \mathrm{LT} / 6)$,

$h_{6}^{\prime}=\cos (\pi \cdot \mathrm{LT} / 4)$,

$h_{7}^{\prime}=\sin (\pi \cdot \mathrm{LT} / 4)$,

$h_{8}^{\prime}=\cos (\pi \cdot \mathrm{LT} / 3)$,

$h_{9}^{\prime}=\sin (\pi \cdot \mathrm{LT} / 3)$,

\section{Appendix B}

\section{The coefficients $\alpha$}

The coefficients $\alpha$ for the $F_{\mathrm{EUV}}$ functional models. Labels out of the table show number of the coefficients $\alpha$. Input parameter "EUV (0.1-50 nm)" must be multiplied by $10^{9}$ when the $F_{\mathrm{EUV}}$ functional model is used. Please contact the corresponding author if you need electric data. 
Table B1.

\begin{tabular}{|c|c|c|c|c|c|c|c|c|c|c|}
\hline & 1 & 2 & 3 & 4 & 5 & 6 & 7 & 8 & 9 & 10 \\
\hline 0 & $4.57 \mathrm{E}+00$ & $8.32 \mathrm{E}+00$ & $-7.08 \mathrm{E}+00$ & $1.45 \mathrm{E}+00$ & $-7.97 \mathrm{E}+00$ & $-2.07 \mathrm{E}+00$ & $-2.51 \mathrm{E}-01$ & $-2.07 \mathrm{E}-01$ & $-6.96 \mathrm{E}-02$ & $9.28 \mathrm{E}+00$ \\
\hline 10 & $-3.87 \mathrm{E}+00$ & $-1.05 E+01$ & $-2.55 E+00$ & $1.64 \mathrm{E}+00$ & $-3.03 \mathrm{E}+00$ & $6.92 \mathrm{E}-01$ & $-1.63 \mathrm{E}+00$ & $3.22 \mathrm{E}-01$ & $4.23 \mathrm{E}+00$ & $-8.35 \mathrm{E}-01$ \\
\hline 20 & $-2.19 \mathrm{E}-01$ & $5.46 \mathrm{E}+00$ & $4.97 \mathrm{E}+00$ & $1.31 \mathrm{E}+00$ & $-3.56 \mathrm{E}+00$ & $2.93 \mathrm{E}-01$ & $3.33 \mathrm{E}-01$ & $-9.63 \mathrm{E}+00$ & $-1.17 \mathrm{E}+01$ & $-1.16 \mathrm{E}+00$ \\
\hline 30 & $-5.26 \mathrm{E}+00$ & $7.87 \mathrm{E}+00$ & $1.82 \mathrm{E}+00$ & $1.18 \mathrm{E}+00$ & $8.15 \mathrm{E}-01$ & $8.54 \mathrm{E}-01$ & $-6.36 \mathrm{E}+00$ & $-7.63 \mathrm{E}+00$ & $-2.81 \mathrm{E}+00$ & $6.57 \mathrm{E}+00$ \\
\hline 40 & $6.65 \mathrm{E}+00$ & $-3.72 \mathrm{E}+00$ & $-2.17 \mathrm{E}+00$ & $6.73 \mathrm{E}-01$ & $-8.91 \mathrm{E}-03$ & $2.53 \mathrm{E}+00$ & $1.88 \mathrm{E}+01$ & $-2.05 \mathrm{E}+00$ & $-6.03 E+00$ & $-5.59 \mathrm{E}+00$ \\
\hline 50 & $-3.27 \mathrm{E}-01$ & $2.05 \mathrm{E}-02$ & $1.92 \mathrm{E}+00$ & $1.75 \mathrm{E}+00$ & $4.09 \mathrm{E}-02$ & $-7.10 \mathrm{E}+00$ & $-2.97 \mathrm{E}+00$ & $-3.06 \mathrm{E}+00$ & $5.50 \mathrm{E}+00$ & $1.69 \mathrm{E}-01$ \\
\hline 60 & $-3.41 \mathrm{E}-01$ & $1.55 \mathrm{E}+00$ & $3.21 \mathrm{E}+00$ & $-7.16 \mathrm{E}-03$ & $-9.65 \mathrm{E}-01$ & $7.50 \mathrm{E}-01$ & $-2.84 \mathrm{E}-02$ & $7.82 \mathrm{E}-01$ & $2.13 \mathrm{E}-01$ & $-4.96 \mathrm{E}-02$ \\
\hline 70 & $5.47 \mathrm{E}-03$ & $1.13 \mathrm{E}-02$ & $-1.04 \mathrm{E}+00$ & $6.06 \mathrm{E}-01$ & $1.14 \mathrm{E}+00$ & $4.36 \mathrm{E}-01$ & $-1.48 \mathrm{E}-01$ & $2.35 \mathrm{E}-01$ & $-1.39 \mathrm{E}-01$ & $1.44 \mathrm{E}-01$ \\
\hline 80 & $-3.56 \mathrm{E}-02$ & $-4.18 \mathrm{E}-01$ & $4.00 \mathrm{E}-02$ & $1.18 \mathrm{E}-01$ & $-3.95 \mathrm{E}-01$ & $-4.58 \mathrm{E}-01$ & $-1.58 \mathrm{E}-01$ & $3.10 \mathrm{E}-01$ & $-5.66 \mathrm{E}-03$ & $-2.50 \mathrm{E}-02$ \\
\hline 90 & $9.11 \mathrm{E}-01$ & $1.14 \mathrm{E}+00$ & $-8.43 \mathrm{E}-02$ & $3.87 \mathrm{E}-01$ & $-8.32 \mathrm{E}-01$ & $-2.15 \mathrm{E}-01$ & $-5.83 \mathrm{E}-02$ & $-5.49 \mathrm{E}-02$ & $-6.22 \mathrm{E}-02$ & $5.12 \mathrm{E}-01$ \\
\hline 100 & 6.61E-01 & $1.82 \mathrm{E}-01$ & $-6.34 \mathrm{E}-01$ & $-5.25 \mathrm{E}-01$ & $3.50 \mathrm{E}-01$ & $2.15 \mathrm{E}-01$ & $-5.42 \mathrm{E}-02$ & $-6.33 \mathrm{E}-03$ & $-1.95 \mathrm{E}-01$ & $-1.62 E+00$ \\
\hline 110 & $1.22 \mathrm{E}-01$ & 4.18E-01 & $4.63 \mathrm{E}-01$ & $-6.11 \mathrm{E}-04$ & $3.40 \mathrm{E}-02$ & $-1.47 \mathrm{E}-01$ & $-1.31 \mathrm{E}-01$ & 4.61E-02 & $6.11 \mathrm{E}-01$ & $1.54 \mathrm{E}-01$ \\
\hline 120 & $2.65 \mathrm{E}-01$ & $-4.49 \mathrm{E}-01$ & $-1.08 \mathrm{E}-02$ & $2.38 \mathrm{E}-02$ & $-1.48 \mathrm{E}-01$ & $-2.95 \mathrm{E}-01$ & $3.03 \mathrm{E}-02$ & $8.08 \mathrm{E}-03$ & $-3.83 \mathrm{E}-02$ & $1.56 \mathrm{E}-03$ \\
\hline 130 & $-1.55 \mathrm{E}-02$ & $-5.37 \mathrm{E}-03$ & $2.80 \mathrm{E}-03$ & $5.88 \mathrm{E}-04$ & 8.61E-04 & $2.48 \mathrm{E}-02$ & $-2.56 \mathrm{E}-02$ & $-3.02 \mathrm{E}-02$ & $-1.30 \mathrm{E}-02$ & $4.71 \mathrm{E}-03$ \\
\hline 140 & $-6.84 \mathrm{E}-03$ & $4.57 \mathrm{E}-03$ & $-4.87 \mathrm{E}-03$ & $1.62 \mathrm{E}-03$ & $1.65 \mathrm{E}-02$ & $-1.69 \mathrm{E}-03$ & $-1.05 \mathrm{E}-02$ & 8.32E-03 & $1.39 \mathrm{E}-02$ & $5.22 \mathrm{E}-03$ \\
\hline 150 & $-8.03 \mathrm{E}-03$ & $-2.06 \mathrm{E}-04$ & $6.16 \mathrm{E}-04$ & $-3.38 \mathrm{E}-02$ & $-2.48 \mathrm{E}-02$ & $1.16 \mathrm{E}-02$ & $-1.90 \mathrm{E}-02$ & $2.24 \mathrm{E}-02$ & $7.45 \mathrm{E}-03$ & $7.76 \mathrm{E}-04$ \\
\hline 160 & $4.77 \mathrm{E}-04$ & $4.19 \mathrm{E}-04$ & $-1.52 \mathrm{E}-02$ & $-1.60 \mathrm{E}-02$ & $-2.16 \mathrm{E}-03$ & $1.78 \mathrm{E}-02$ & $1.14 \mathrm{E}-02$ & $-1.03 \mathrm{E}-02$ & $-5.52 \mathrm{E}-03$ & $1.52 \mathrm{E}-03$ \\
\hline 170 & $-2.32 \mathrm{E}-04$ & $5.06 \mathrm{E}-03$ & $4.35 \mathrm{E}-02$ & $-2.79 \mathrm{E}-03$ & $-9.47 \mathrm{E}-03$ & $-1.20 \mathrm{E}-02$ & $1.19 \mathrm{E}-03$ & $-1.26 \mathrm{E}-03$ & $3.69 \mathrm{E}-03$ & $2.57 \mathrm{E}-03$ \\
\hline 180 & $-4.12 \mathrm{E}-03$ & $-1.59 \mathrm{E}-02$ & $-6.81 \mathrm{E}-05$ & $-7.30 \mathrm{E}-03$ & $1.11 \mathrm{E}-02$ & $-7.69 \mathrm{E}-05$ & $-6.57 \mathrm{E}-04$ & $4.36 \mathrm{E}-03$ & $8.17 \mathrm{E}-03$ & $-2.34 \mathrm{E}-04$ \\
\hline 190 & $-9.01 \mathrm{E}-07$ & $3.16 \mathrm{E}-04$ & $-2.92 \mathrm{E}-06$ & $7.82 \mathrm{E}-05$ & $4.01 \mathrm{E}-05$ & $-3.24 \mathrm{E}-05$ & $-1.51 \mathrm{E}-05$ & $-8.72 \mathrm{E}-06$ & $-1.49 \mathrm{E}-04$ & $2.32 \mathrm{E}-04$ \\
\hline 200 & $1.91 \mathrm{E}-04$ & $1.04 \mathrm{E}-04$ & $-4.63 \mathrm{E}-05$ & $5.27 \mathrm{E}-05$ & $-4.13 \mathrm{E}-05$ & $4.20 \mathrm{E}-05$ & $-1.52 \mathrm{E}-05$ & $-1.74 \mathrm{E}-04$ & $3.04 \mathrm{E}-05$ & $1.52 \mathrm{E}-04$ \\
\hline 210 & $-4.35 \mathrm{E}-05$ & $-1.32 \mathrm{E}-04$ & $-5.01 \mathrm{E}-05$ & $6.30 \mathrm{E}-05$ & $4.70 \mathrm{E}-06$ & $-7.32 \mathrm{E}-06$ & $2.83 \mathrm{E}-04$ & $1.47 \mathrm{E}-04$ & $-1.17 \mathrm{E}-04$ & $6.63 \mathrm{E}-05$ \\
\hline 220 & $-1.70 \mathrm{E}-04$ & $-6.90 \mathrm{E}-05$ & $6.19 \mathrm{E}-06$ & 4.81E-06 & $2.28 \mathrm{E}-06$ & $1.25 \mathrm{E}-04$ & $1.29 \mathrm{E}-04$ & $-4.69 \mathrm{E}-06$ & $-1.54 \mathrm{E}-04$ & $-7.02 \mathrm{E}-05$ \\
\hline 230 & $9.07 \mathrm{E}-05$ & $4.16 \mathrm{E}-05$ & $-1.50 \mathrm{E}-05$ & $5.58 \mathrm{E}-06$ & $-5.32 \mathrm{E}-05$ & $-3.60 \mathrm{E}-04$ & $3.62 \mathrm{E}-05$ & $7.29 \mathrm{E}-05$ & $1.05 \mathrm{E}-04$ & $-1.40 \mathrm{E}-05$ \\
\hline 240 & $1.21 \mathrm{E}-05$ & $-2.70 \mathrm{E}-05$ & $-1.53 \mathrm{E}-05$ & $6.52 \mathrm{E}-05$ & $1.23 \mathrm{E}-04$ & $-3.43 \mathrm{E}-05$ & $6.15 \mathrm{E}-05$ & $-8.46 \mathrm{E}-05$ & $2.57 \mathrm{E}-06$ & $4.16 \mathrm{E}-06$ \\
\hline 250 & $-3.89 \mathrm{E}-05$ & $-7.10 \mathrm{E}-05$ & & & & & & & & \\
\hline
\end{tabular}

Acknowledgements. The authors wish to thank M. Yamada at Max Planck Institute for Solar System Research, Germany for usueful informations to construct the functional models.

Topical Editor M. Pinnock thanks I. Kutiev and another anonymous referee for their help in evaluating this paper.

\section{References}

Baldwin, M. P., Gray, L. J., Dunkerton, T. J., Hamilton, K., Haynes, P. H., Randel, W. J., Holton, J. R., Alexander, M. J., Hirota, I., Horinouchi, T. Jones, D. B. A., Kinnersley, J. S., Marquardt, C., Sato, K., and Takahashi, M.: The quasi-biennial oscillation, Rev. Geophys., 39, 179-230, 2001.

Banks, P. M. and Kockarts, G. (Eds.): Aeronomy: Part A, Academic Press, New York, 1973.

Bilitza, D.: The importance of EUV indices for the International Reference Ionosphere, Phys. Chem. Earth, Part C, 25(5-6), 515521, 2000.

Bilitza, D.: International Reference Ionosphere 2000, Radio Sci., 36(2), 261-275, 2001.

Bilitza, D.: A correction for the IRI topside electron density model based on Aloutte/ISIS topside sounder data, Adv. Space Res., 33, 838-843, 2004.

Bilitza, D. and Williamson, R.: Towards a better representation of the IRI topside based on ISIS and alouette data, Adv. Space Res., 25(1), 149-152, 2000.

Bilitza, D., Reinsch, B. W., Radicella, S., Pulinets, S., Gulyaeva, T., and Triskova, L.: Improvements of the international reference ionosphere model for the topside electron density profile, Radio Sci., 41, RS5S15, doi:10.1029/2005RS003370, 2006.

Coïsson, P., Radicella, S. M., Nava, B., and Leitinger, R.: Low and equatorial latitudes topside in NeQuick, J. Atmos. Solar-Terr. Phys., 70, 901-906, 2008a.

Coïsson, P., Radicella, S. M., Ciraolo, L., Leitinger, R., and Nava, B.: Global validation of IRI TEC for high and medium solar activity conditions, Adv. Space, Res., 42, 770-775, doi:10.1016/j.asr.2007.09.002, 2008b.

Di Giovanni, G. and Radicella, S. M.: An analytical model of the electron density profile in the ionosphere, Adv., Space Res., 10(11), 27-30, 1990.

Forbes, J. M., Russell, J., Miyahara, S., Zhang, X., Palo, S., Mlynczak, M., Mertens, C. J., and Hagan, M. E.: Tropospherethermosphere tidal coupling as measured by the SABER instrument on TIMED during July-September 2002, J. Geophys. Res., 111, A10S06, doi:10.1029/2005JA011492, 2006.

Fujiwara, H., Maeda, S., Fukunishi, H., Fuller-Rowell, T. J., and Evans, D. S.: Global variations of thermospheric winds and temperatures caused by substorm energy injection, J. Geophys. Res., 101, 225-239, 1996.

Habarulema, J. B., McKinnel, L.-A., and Cilliers, P. J.: Prediction of global positioning system total electron content using Neural Networks over South Africa, J. Atmos. Solar-Terr. Phys., 69, 1842-1850, 2007.

Immel, T. J., Sagawa, E., England, S. L., Henderson, S. B., Hagan, M. E., Mende, S. B., Frey, H. U., Swenson, C. M., and Paxton, L. J.: Control of equatorial ionospheric morphology by atmospheric tides, Geophys. Res. Lett., 33, L15108, doi:10.1029/2006GL026161, 2006. 
Iwamoto, I., Katoh, H., Maruyama, T., Minakoshi, H., Watari, S., and Igarashi, K.: Latitudinal variations of solar flux dependence in the topside plasma density: comparison between IRI model and observations, Adv. Space Res., 29, 877-882, 2002.

Judge, D. L., McMullin, D. R., Ogawa, S., Hovestadt, D., Klecker, B., Hilchenbach, M., Canfield, L. R., Vest, R. E., Watts, R., Tarrio, C., Kuhne, M., and Wurz, P.: First solar EUV irradiances obtained from SOHO by the CELIAS/SEM, Solar Phys., 177, 161-173, 1998.

Kakinami, Y., Watanabe, S., and Oyama, K.-I.: An empirical model of electron density in low latitude at $600 \mathrm{~km}$ obtained by Hinotori satellite, Adv. Space Res., 41, 1494-1498, doi:10.1016/j.asr.2007.09.031, 2008.

Kane, R. P.: Fluctuations in the $\sim 27$-day sequences in the solar index F10 during solar cycles 22-23, J. Atmos. Sol.-Terr. Phys., 65, 1169-1174, 2003.

Kane, R. P.: Solar EUV and ionospheric parameters: A brief assessment, Adv. Space Res., 32(9), 1713-1718, 2003.

Kutiev, I. and Marinov, P.: Topside sounder model of scale height and transition height characteristics of the ionosphere, Adv. Space, Res., 39, 759-766, 2007.

Leick, A.: GPS Satellite Surveying, 560 pp., John Wiley, Hoboken, N. J., 1995.

Liu, J. Y., Tsai, H. F., and Jung, T. K.: Total electron content obtained by using the global positioning system, Terr. Atmos. Ocean. Sci., 7, 107-117, 1996.

Liu, J. Y., Chen, Y. I., Pulinets, S. A., Tsai, Y. B., and Chuo, Y. J.: Seismo-ionospheric signatures prior to $\mathrm{M}>=6.0$ Taiwan earthquakes, Geophys. Res. Lett., 27, 3113-3116, doi:10.1029/2000GL011395, 2000.

Liu, J. Y., Chen, Y. I., Chuo, Y. J., and Tsai, H. F.: Variations of ionospheric total electron content during the Chi-Chi earthquake, Geophys. Res. Lett., 28, 1383-1386, 2001.

Liu, J. Y., Chuo, Y. J., Shan, S. J., Tsai, Y. B., Chen, Y. I., Pulinets, S. A., and Yu, S. B.: Pre-earthquake ionospheric anomalies registered by continuous GPS TEC measurements, Ann. Geophys., 22, 1585-1593, 2004, http://www.ann-geophys.net/22/1585/2004/.

Liu, J. Y., Tsai, Y. B., Ma, K. F., Chen, Y. I., Tsai, H. F., Lin, C. H., Kamogawa, M., and Lee, C. P.: Ionospheric GPS total electron content (TEC) disturbances triggered by the 26 December 2004 Indian Ocean tsunami, J. Geophys. Res., 111, A05303, doi:10.1029/2005JA011200, 2006a.

Liu, L., Wan, W., Ning, B., Pirog, O. M., and Kurkin, V. I.: Solar activity variations of the ionospheric peak electron density, J. Geophys. Res., 111, A08304, doi:10.1029/2006JA011598, 2006b.

Lin, C. H., Wang, W., Hagan, M. E., Hsiao, C. C., Immel, T. J., Hsu, M. L., Liu, J. Y., Paxton, L. J., Fang, T. W., and Liu, C. H.: Plausible effect of atmospheric tides on the equatorial ionosphere observed by the FORMOSAT-3/COSMIC: Three-dimensional electron density structures, Geophys. Res. Lett., 34, L11112, doi:10.1029/2007GL029265, 2007.

Marinov, P., Kutiev, I., and Watanabe, S.: Empirical model of $\mathrm{O}^{+}$ $\mathrm{H}^{+}$transition height based on topside sounder data, Adv. Space Res, 34, 2021-2025, 2004.
Mannucci, A. J., Wilson, B. D., Yuan, D. N., Ho, C. H., Lindqwister, U. J., and Runge, T. F.: A global mapping technique for GPSderived ionospheric total electron content measurements, Radio Sci., 33, 565-582, 1998.

Oyama, K.-I., Watanabe, S., Su, Y., Takahashi, T., and Hirao, K. Season, local time, and longitude variations of electron temperature at the height of $\sim 600 \mathrm{~km}$ in the low latitude region, Adv. Space Res., 18(6), 269-278, 1996.

Rawer, K., Bilitza, D., and Ramakrishnan, S.: Goals and status of international reference ionosphere, Rev. Geophys., 16, 177-181, 1978.

Richards, P., Fennelly, J., and Torr, D.: EUVAC: A Solar EUV Flux Model for Aeronomic Calculations, J. Geophys. Res., 99, 89818992, 1994a

Richards, P., Fennelly, J., and Torr, D.: Correction to "EUVAC: A Solar EUV Flux Model for Aeronomic Calculations", J. Geophys. Res., 99, 13283-13283, 1994b.

Richmond, A. D.: Gravity wave generation, propagation, and dissipation in the thermosphere, J. Geophys. Res., 83, 4131-4145, 1978.

Sardón, E., Rius, A., and Zarraoa, N.: Estimation of the transmitter and receiver differential biases and the ionospheric total electron content from global positioning system observation, Radio Sci., 29, 577-586, 1994

Saito, A., Nishimura, M., Yamamoto, M., Fukao, S., Kubota, M., Shiokawa, K., Otsuka, Y., Tsugawa, T., Ogawa, T., Ishii, M., Sakanoi, T., and Miyazaki, S.: Traveling ionospheric disturbances detected in the FRONT campaign, Geophys. Res. Let., 28, 689-692, 2001.

Sagawa, E., Immel, T. J., Frey, H. U., and Mende, S. B.: Longitudinal structure of the equatorial anomaly in the nighttime ionosphere observed by IMAGE/FUV, J. Geophys. Res., 110, A11302, doi:10.1029/2004JA010848, 2005.

Shiokawa, K., Otsuka, Y., Ogawa, T., Balan, N., Igarashi, K., Ridley, A. J., Knipp, D. J., Saito, A., and Yumoto, K.: A large-scale traveling ionospheric disturbance during the magnetic storm of 15 September 1999, J. Geophys. Res., 107, 1088, doi:10.1029/2001JA000245, 2002.

Tsugawa, T., Saito, A., Otsuka, Y., and Yamamoto, M.: Damping of large-scale traveling ionospheric disturbances detected with GPS networks during the geomagnetic storm, J. Geophys. Res. 108, 1127, doi:10.1029/2002JA009433, 2003.

Uozumi, T., Yomoto, K., Kitamura, K., Abe, S., Kakinami, Y., Shinohara, M., Yoshikawa, A., Kawano, H., Ueno, T., Tokunaga, T., McNamara, D., Ishituka, J. K., Dutra, S. L. G., Damie, B., Doumbia, V., Obrou, O., Rabiu, A. B., Adimula, I. A., Othman, M., Fairos, M., Otadoy, R. E. S., and MAGDAS Group: A new index to monitor temporal and long-term variations of the equatorial electrojet by MAGDAS/CPMN real-time data: EE-index, Earth Planets Space Lett., 60, 785-790, 2008. 